\title{
Isolation and characterization of Salmonella paratyphi phage and its lytic spectrum that correlation with pili
}

Liming Jiang ( $\square$ jiangliming@nbu.edu.cn )

Ningbo university

Rui Zheng

First People's Hospital of Yunnan

Research article

Keywords: Salmonella, phage, lytic, spectrum, biofilm, antibiotic

Posted Date: June 8th, 2020

DOI: https://doi.org/10.21203/rs.3.rs-29967/v1

License: (c) (i) This work is licensed under a Creative Commons Attribution 4.0 International License.

Read Full License 


\section{Abstract \\ Background}

Prevention and control of Salmonella biofilm have great importance for economic point and medical. Phages and their derivatives are ideal candidates for replacing or compensating of antibiotic problems in the future.

\section{Results}

In this study, the phage KM16 was isolated from slaughterhouse sump samples. It belonged to the Myoviridae family and optimal growth temperature was $42{ }^{\circ} \mathrm{C}$, the $\mathrm{pH}$ of optimal preservation buffer was $6 \sim 7$, optimal multiplicity of infection (MOI) was 0.0001 and the genome size was 170,126 bp. The phage KM16 has the ability to lytic most clinical strains of Salmonella paratyphi A and Salmonella paratyphi B. Phylogenetic analysis found that the 16S rRNA, crispr 1 and fimA genes of Salmonella paratyphi have a high similarity and correlation with lytic spectrum of phage KM16, but not correlated with the genes of invA, isrK and luxS. Above all, the lytic spectrum of phage KM16 correlation with tertiary structure of Salmonella pili, the pili of Salmonella was the recognition site for phage adsorption. Collaboration of phage KM16 and antibiotics have better anti-biofilm effect than alone of phage or antibiotics in low concentration of bacteria culture and phage have better anti-biofilm effect than antibiotics in a high concentration of bacteria culture.

\section{Conclusions}

The data of this study provided a new perspective to understand the relationship between phage lytic spectrum and difference of host strains.

\section{Background}

Salmonella as the most serious foodborne pathogens among worldwide and it was distributing widely over natural environment, in addition, it was widely existed on all kinds of food and food raw materials [1]. Salmonella mainly lodges in common domestic animals, and humans are also one of its main hosts. It's a serious zoonosis original microbes, which not only cause disease in livestock, poultry animals, rats and mice, but also cause of food poisoning in human [2]. Majowicz and Deng have reported there are 94 million gastroenteritis cases and 155, 000 people deaths caused by Salmonella in the world every year $[3,4]$.

Biofilm was a multicellular community of microorganisms where microorganisms are embedded selfproduced extracellular matrix and attached to highly hydrated extracellular matrixon, non-biological and biological surfaces [5-7]. The extracellular polymeric substances matrix of biofilm acts as a barrier that 
reduces the penetration of antimicrobial agents and microbiotic into the interior of the biofilm $[8,9]$. Biofilm of microorganism are highly resistant to desiccation, heat, antibiotics and acidic condition [10]. Bacteria in the biofilm are approximately 10 to 1000 times less sensitive to antimicrobial agents than planktonic bacteria, on account of extracellular polymeric substances of the biofilm that prevent contact with antimicrobial agents $[11,12]$. This makes totally eliminate of biofilm in clinic, food industry and husbandry are scarcely possible [13].

Penicillin has been around since 1943, since then antibiotics play an important role in controlling bacterial infections and protecting human health. Nevertheless, with the aggravation of antibiotic abuse, widespread drug resistance problems, adverse consequences and serious harm have been caused. As early as 2003 , statistics from the ministry of health, PRC showed that the annual death toll caused by the abuse of antibiotics in China was as high as 80,000 . The food industry and clinic faces a serious Salmonella contamination problem, what is more exacerbated by the overuse of antibiotics, resulting in an increasing number of antibiotic-resistant foodborne and clinic Salmonella. Efforts to develop new ways to control Salmonella contamination in food and its processing environment are important. The applications of antibiotics and disinfectants at stationary phases to eradicate Salmonella biofilms could be have adverse effects on human health [14].

Phages and their derivatives can be used as a novel, feasible, and safe biological product for the prevention, treatment, and elimination of Salmonella in food, clinic and food processing environments. Phages and their derivatives are ideal candidates for replacing or compensating for antibiotic problems of the future [15]. Phages are viruses that with bacterial lysis activity $[16,17]$. Due to the ability of kill bacteria, which appear to be a good alternative to antimicrobials and disinfectants [18]. Above all, phages infect only bacteria and not be harmful to humans, making them safe for apply to clinic and food products [19]. Recent study found that that phage has high efficiency in reducing and control bacterial biofilms on various surfaces formed by Escherichia coli, Salmonella, Listeria monocytogenes and Pseudomanas aeruginosa [20-24].

Prevention and control of contamination caused by multidrug-resistance (MDR) bacteria of Salmonella has great importance for an economic point of view and medical [25]. The main challenges for such a phage therapy of the relatively narrow lytic range against bacterial strain [26]. Here we report a new isolated lytic phages named KM16 have better anti-biofilm effect than antibiotics in high concentration of bacteria. In addition, phylogenetic analysis found that the lytic spectrum of phage KM16 correlation with tertiary structure of Salmonella pili, the pili of Salmonella was the recognition site for phage adsorption.

\section{Results}

\section{Characteristics and morphology of isolated phages}

Virulent phage KM16 was isolated from the samples of slaughterhouse sump that according to the host of Salmonella paratyphi NA3. The plaque of phage KM16 was appeared $1 \mathrm{~mm}$ in diameter after overnight incubation at $37^{\circ} \mathrm{C}$ (Figure 1). 
Negatively stained of purified phage KM16 was observed with an electron microscope. Transmission electron microscopy (TEM) revealed KM16 virions with an icosahedral head $110 \pm 5 \mathrm{~nm}$ in diameter, and a non contractile tail $110 \pm 5 \mathrm{~nm}$ long (Figure 2). The morphology of phage KM16 indicated they belonged to the Myoviridae family.

After standing for 5 min at $15{ }^{\circ} \mathrm{C}$, nearly $85 \%$ of phage particles were adsorbed to the host bacteria, after incubation for $20 \mathrm{~min}$, almost all phages were adsorbed to host bacteria (Figure 3). A growth curve of the phage KM16 was obtained by inoculation on Salmonella paratyphi A NA3 according to MOI of 0.1 at $37^{\circ} \mathrm{C}$ (Fig. 3). The latent period of phage KM16 was 60 min. The titer of phage KM16 were explosive growth before $170 \mathrm{~min}$ and reached peak at $9 \mathrm{~h}$, and then it's appear going down at $15 \mathrm{~h}$ later. The amplification factor of phage KM16 was approximately 200 times.

\section{Optimum temperature, $\mathrm{pH}$ and $\mathrm{MOI}$ of isolated phages}

The phage titer of KM16 was measured by the double plate method at different temperature after $1 \mathrm{~h}$ of processed. KM16 have the highest activity after treatment for $1 \mathrm{~h}$ at $42^{\circ} \mathrm{C}$, then there was a noticeable decline at $50{ }^{\circ} \mathrm{C}$ and complete inactivation until $90{ }^{\circ} \mathrm{C}$ (Figure 4). The result show that phage KM16 have low temperature adaptability and which consistent with the optimum survival temperature of it's host.

Phage KM16 have the most plaque at $\mathrm{pH}=6 \sim 7$, further, plaque at $\mathrm{pH}=10 \sim 11$ were significantly higher than that at pH3 4 (Figure 4). These results indicated that the phage KM16 have good tolerance to alkali but extremely intolerant to acids.

Multiplicity of infection (MOI) refers the ratio of the number of phages to cells. The optimum $\mathrm{MOI}$ of phage KM16 were 0.0001 , among them, the plaque of KM16 were decreased significantly after 0.001 and reach minimum at $\mathrm{MOI}=100$ (Fig. 4).

\section{DNA extractionपrestriction endonuclease digestion and genome analysis}

The genome size of phage KM16 is 170,126 bp. We have identified 278 protein-coding genes for KM16 genome (Table S1). KM16 genome DNA was digested by EcoRI, Hind III, Notl and Xhol I. This is consistent with the results of phage genome analysis of that phage KM16 has more endonuclease sites. Genome analysis revealed that phage KM16 was virulent phages (Figure 5,6,).

Phages bacteriostasis spectrum, host resistance and phylogenetic analysis the genes of $16 \mathrm{~S}$, host biofilm and crispr

\section{Antimicrobial susceptibility}

The Salmonella paratyphi A and Salmonella paratyphi B were isolated from clinical patients in the laboratory of first people's hospital of Yunnan province. Unfortunately, they have a broad spectrum of resistance (Table 1), but fortunately, most of them can be removed by the phage of KM16 (Table 2). They 
are all possess resistant to penicillin, streptomycin, cefoxitin, gentamicin, ciprofloxacin and tobramycin, but sensitive to kanamycin sulfate and macrodantin.

Table 1. Antibiotic resistance of Salmonella isolates used in this study

\begin{tabular}{lllllllllllll}
\hline \multicolumn{11}{c}{ Salmonella paratyphi A } & \multicolumn{1}{c}{ Salmonella paratyphi B } \\
\hline Antibiotic & $\mathrm{A}$ & $\mathrm{B}$ & $\mathrm{C}$ & $\mathrm{D}$ & $\mathrm{E}$ & $\mathrm{F}$ & $\mathrm{JL} 1$ & $\mathrm{JJ} 9$ & $\mathrm{NA} 5$ & $\mathrm{NA} 3$ & $\mathrm{G}$ & $\mathrm{H}$ \\
Penicillin & $\mathrm{R}$ & $\mathrm{R}$ & $\mathrm{R}$ & $\mathrm{R}$ & $\mathrm{R}$ & $\mathrm{R}$ & $\mathrm{R}$ & $\mathrm{R}$ & $\mathrm{R}$ & $\mathrm{R}$ & $\mathrm{R}$ & $\mathrm{R}$ \\
Streptomycin & $\mathrm{R}$ & $\mathrm{R}$ & $\mathrm{R}$ & $\mathrm{R}$ & $\mathrm{R}$ & $\mathrm{R}$ & $\mathrm{R}$ & $\mathrm{R}$ & $\mathrm{R}$ & $\mathrm{R}$ & $\mathrm{R}$ & $\mathrm{R}$ \\
kanamycin sulfate & $\mathrm{S}$ & $\mathrm{S}$ & $\mathrm{S}$ & $\mathrm{S}$ & $\mathrm{S}$ & $\mathrm{S}$ & $\mathrm{S}$ & $\mathrm{S}$ & $\mathrm{S}$ & $\mathrm{S}$ & $\mathrm{S}$ & $\mathrm{S}$ \\
cefoxitin & $\mathrm{R}$ & $\mathrm{R}$ & $\mathrm{R}$ & $\mathrm{R}$ & $\mathrm{R}$ & $\mathrm{R}$ & $\mathrm{R}$ & $\mathrm{R}$ & $\mathrm{R}$ & $\mathrm{R}$ & $\mathrm{R}$ & $\mathrm{R}$ \\
ampicillin & $\mathrm{S}$ & $\mathrm{S}$ & $\mathrm{S}$ & $\mathrm{S}$ & $\mathrm{S}$ & $\mathrm{R}$ & $\mathrm{S}$ & $\mathrm{S}$ & $\mathrm{S}$ & $\mathrm{S}$ & $\mathrm{S}$ & $\mathrm{R}$ \\
gentamicin & $\mathrm{R}$ & $\mathrm{R}$ & $\mathrm{R}$ & $\mathrm{R}$ & $\mathrm{R}$ & $\mathrm{R}$ & $\mathrm{R}$ & $\mathrm{R}$ & $\mathrm{R}$ & $\mathrm{R}$ & $\mathrm{R}$ & $\mathrm{R}$ \\
aztreonam & $\mathrm{S}$ & $\mathrm{S}$ & $\mathrm{S}$ & $\mathrm{S}$ & $\mathrm{S}$ & $\mathrm{S}$ & $\mathrm{S}$ & $\mathrm{S}$ & $\mathrm{S}$ & $\mathrm{S}$ & $\mathrm{S}$ & $\mathrm{R}$ \\
ceftriaxone & $\mathrm{S}$ & $\mathrm{S}$ & $\mathrm{S}$ & $\mathrm{S}$ & $\mathrm{S}$ & $\mathrm{S}$ & $\mathrm{S}$ & $\mathrm{S}$ & $\mathrm{S}$ & $\mathrm{S}$ & $\mathrm{S}$ & $\mathrm{R}$ \\
Ciprofloxacin & $\mathrm{R}$ & $\mathrm{R}$ & $\mathrm{R}$ & $\mathrm{R}$ & $\mathrm{R}$ & $\mathrm{R}$ & $\mathrm{R}$ & $\mathrm{R}$ & $\mathrm{R}$ & $\mathrm{R}$ & $\mathrm{R}$ & $\mathrm{R}$ \\
levofloxacin & $\mathrm{S}$ & $\mathrm{S}$ & $\mathrm{S}$ & $\mathrm{S}$ & $\mathrm{S}$ & $\mathrm{S}$ & $\mathrm{S}$ & $\mathrm{S}$ & $\mathrm{S}$ & $\mathrm{S}$ & $\mathrm{S}$ & $\mathrm{S}$ \\
tobramycin & $\mathrm{R}$ & $\mathrm{R}$ & $\mathrm{R}$ & $\mathrm{R}$ & $\mathrm{R}$ & $\mathrm{R}$ & $\mathrm{R}$ & $\mathrm{R}$ & $\mathrm{R}$ & $\mathrm{R}$ & $\mathrm{R}$ & $\mathrm{R}$ \\
macrodantin & $\mathrm{S}$ & $\mathrm{S}$ & $\mathrm{S}$ & $\mathrm{S}$ & $\mathrm{S}$ & $\mathrm{S}$ & $\mathrm{S}$ & $\mathrm{S}$ & $\mathrm{S}$ & $\mathrm{S}$ & $\mathrm{S}$ & $\mathrm{S}$ \\
\hline
\end{tabular}

The lytic phage of Salmonella paratyph KM16 was able to infect most strains of Salmonella paratyphi which were isolated from The First People Hospital of Yunnan Province, China (Table 2). The Salmonella paratyphi A JJ9 and Salmonella paratyphi A NA3 exhibited sensitivity to KM16. This analysis underlined the wide host range of the isolated phage KM16.

Table 2. Host range analysis of phage KM16.

\begin{tabular}{ll}
\hline Strain & KM16 \\
\hline Salmonella paratyphi A-A & + \\
Salmonella paratyphi A-B & + \\
Salmonella paratyphi A-C & + \\
Salmonella paratyphi A-D & + \\
Salmonella paratyphi A-E & + \\
Salmonella paratyphi A-F & + \\
Salmonella paratyphi A-JL1 & + \\
Salmonella paratyphi A-JJ9 & + \\
Salmonella paratyphi A-NA5 & + \\
Salmonella paratyphi A-NA3 & + \\
Salmonella paratyphi B-G & - \\
Salmonella paratyphi B-H & - \\
\hline
\end{tabular}

\section{Phylogenetic analysis.}

The genes of 16S rRNA (bacterial systematics), crispr 1 (Clustered regularly interspaced short palindromic repeats, an immune weapon produced by bacteria and phages fighting each othe), fimA (Salmonella pili), invA (Virulence genes), isrK (Quorum sensing gene) and luxS (Quorum sensing gene) of Salmonella paratyphi were aligned for phylogenetic analysis. Phylogenetic tree analysis indicated that genes of $16 \mathrm{~S}$, crispr 1 and fimA of Salmonella paratyphi have a high similarity and correlation with lytic spectrum of phage KM16, but not correlated with genes of invA, isrKand IUxS. The results indicate that the relatedness, immune system and pili of host were corresponded with the lytic spectrum of phage, 
nevertheless, the virulence, and quorum sensing of host were not corresponded with the lytic spectrum of phage (Figure 7).

\section{Structure of Salmonella fimA (pili) protein}

The pili of Salmonella was the recognition site for phage adsorption. Comparison of Salmonella fimA among Salmonella paratyphi A-A, Salmonella paratyphi A-NA3 and Salmonella paratyphi B-H using SWISS-MODEL (https://swissmodel.expasy.org/) for tertiary structure prediction. SWISS-MODEL searches with other Salmonella fimA with experimentally solved tertiary structure revealed a significant match (https://www.rcsb.org/structure/6erj) (Figure 8). There were an significant differences tertiary structure of Salmonella pili among phage KM16 sensitive and resistant strains (Figure 8).

\section{Compare the effects of phages and antibiotics on host biofilms}

The effects of KM16 (MOI=0.1) and kanamycin sulfate $(10 \mu \mathrm{g} / \mathrm{mL})$ on round coverslip of Salmonella paratyphi A NA3 biofilm were assessed through Scanning electron micrograph (SEM). In this case of Salmonella paratyphi A NA3 seed solution inoculation at a rate of $1 / 250$, added KM16 (MOI=0.1) and kanamycin sulfate $(10 \mu \mathrm{g} / \mathrm{mL})$ in immediately and culture for $24 \mathrm{~h}$, antibiotics have better sterilization effect than phages whether in the results of scanning electron micrograph, $\mathrm{OD}_{600}$ of bacterial culture solution, or microplate reader $\mathrm{OD}_{570}$ of bacterial biofilm (Fig. 9, 10).

Nevertheless, In another case of Salmonella paratyphi A NA3 seed solution inoculation at a rate of 1/250 and culture for $12 \mathrm{~h}$ later, then $\mathrm{KM} 16(\mathrm{MOI}=0.1)$ and kanamycin sulfate $(10 \mu \mathrm{g} / \mathrm{mL})$ were added and cultured for $12 \mathrm{~h}$, phages have better sterilization effect than antibiotics whether in the results of scanning electron micrograph, $\mathrm{OD}_{600}$ of bacterial culture solution, or microplate reader $\mathrm{OD}_{570}$ of bacterial biofilm (Fig. 9, 10). In addition, in case of of Salmonella paratyphi A NA3 seed solution inoculation at a rate of $1 / 250$ and culture for $12 \mathrm{~h}$ later, then $\mathrm{KM} 16(\mathrm{MOI}=0.1)$ and kanamycin sulfate $(10 \mu \mathrm{g} / \mathrm{mL})$ were added and cultured for $12 \mathrm{~h}$, collaboration of phage and antibiotics have better sterilization effect than

alone of phages or antibiotics whether in the results of scanning electron micrograph, $\mathrm{OD}_{600}$ of bacterial culture solution, or microplate reader $\mathrm{OD}_{570}$ of bacterial biofilm (Figure 9,10 ).

The result of host colony-forming unit indicate collaboration of phage and antibiotics have better sterilization effect than alone of phage or antibiotics (Figure 11). Meanwhile, under the case of Salmonella paratyphi A NA3 seed solution inoculation at a rate of $1 / 250$ and culture for $12 \mathrm{~h}$ later, then KM16 (MOI=0.1) and kanamycin sulfate $(10 \mu \mathrm{g} / \mathrm{mL})$ were added and cultured for $12 \mathrm{~h}$, phages have better sterilization effect than antibiotics (Figure 11).

\section{Discussion}

Salmonella is a common foodborne pathogen, which mainly found in contaminated food and cause severe medical problems and foodborne diseases $[27,28]$. The Salmonella paratyphi A NA3 used in this study was isolated from a clinical patient in the first people's hospital of Yunnan province, China who 
accidentally ate Salmonella contaminated bread. It's regrettable of that overuse of antibiotics has increased the severity of salmonella [29]. The main reasons of drug resistance was that antibiotic resistance (AR) and multidrug-resistance (MDR) genes were in the genome of almost all Salmonella strains [30].

The isolated Salmonella phage KM16 belongs to Myoviridae and the genome sizes was 170, $126 \mathrm{bp}$. Corresponding, the geonme sizes of Salmonella phage $\Phi$ Stp1 was 112,149 bp and Salmonella phages SPFM was 233 to $242 \mathrm{~Kb}$, the consistent part was they all belong to the Myoviridae family [31, 32].

With the rise of antibiotic abuse, multiple resistant bacteria and superbacteria hence a public health hazard. Alternatives to antibiotics are urgently needed, phage, are dawn of this increasing drug resistance. The isolated Salmonella phages KM16 were ideal substitute for antibiotics for they can lysin multidrug-resistant bacteria. What's more, phages have better sterilization effect than antibiotics in a high concentration of bacteria, and that, collaboration of phages and antibiotics have better sterilization effect than alone of phages or antibiotics in a low concentration medium of bacteria (Fig. 9,10,11).

Phylogenetically of Salmonella paratyphi fimA reveal that has a high similarity and correlation with lytic spectrum of phage KM16. Similar results were found that tail fiber adhesion features was a rare polyglycine rich domain for host recognition of Salmonella phage S16 [33]. Furthermore, the deficient outer core of lipopolysaccharides was proposed for Escherichia coli 0157:H7 KIT03 recognise and infect host bacteria [34].

The ability of Salmonella to form biofilms on different food surfaces increases the risk of crosscontamination, particularly in poultry products, which was a serious problem for food industries and public health [35-37]. Although the significant problems in pathogen control caused by biofilms, exploiting effective eliminate of biofilms is still challenging [38]. Until now, there is no ideal technology of biofilm control, hence, the new control strategies for biofilm are constantly recommended [39]. In this study, we demonstrated that the phage KM16 and kanamycin sulfate reduced biofilm formation of Salmonella.

The phage cleavage spectrum was the bottleneck of phage wide application. At present, some studies have reported that the phage cleavage spectrum is related to the phage itself and the host. For phage, Wu., et al. have found that the endolysin of Acinetobacter baumannii PD-6A3 with activity of extended lytic [40], Sergueev., et al. have reported that a distinct allele in hypervariable complex repeat structure in the Sb-1 genome correlated with phage lytic spectrum [41], Olszak., et al. have found that the jumbo phage in the bacterial population correlates with reduced Pseudomonas aeruginosa virulence [42]. For the host, Benešík., et al. have found that the binding spectrum of SH3b domain of Kayvirus endolysin LysF1 was a promising feature for creating new chimeolysins through combining it with more effective catalytic domains [43], Hoai., et al. have reported that the phage cleavage spectrum of Lactococcus garvieae affected by bacterial capsule and phage [44]. 
The result shown that phage KM16 and kanamycin sulfate can infect Salmonella biofilm and has the potential to reduce tested Salmonella paratyphi A NA3 strains. Antibiotics have better anti-biofilm effect than phages in a low concentration medium of bacteria (Fig. 9,10,11). Nonetheless, phages have better anti-biofilm effect than antibiotics in a high concentration of bacteria, and that, collaboration of phages and antibiotics have better anti-biofilm effect than alone of phages or antibiotics in a low concentration medium of bacteria (Fig. 9,10,11). The data of this study provided the strong evidence that the application of phage could reduce the growth and biofilm of Salmonella that are important to maintain public health.

\section{Conclusions}

In this work, we have found the host specific lytic effect of Salmonella paratyphi phage correlation with tertiary structure of Salmonella pili, which this research provided a new perspective to understand the relationship between phage lytic spectrum and difference of host strains, this is important in field of phage lytic spectrum knowledge. Collaboration of phage KM16 and kanamycin sulfate have better antibiofilm effect than alone of KM16 and kanamycin sulfate in low concentration of bacterial culture, KM16 has better anti-biofilm effect than kanamycin sulfate in high concentration of bacterial culture. The data of this study provided a strong evidence of application phage to reduce the growth of Salmonella biofilm of which were important for public health.

\section{Methods}

\section{Bacterial strains and growth conditions}

Salmonella paratyphi A NA3 was isolated from the patient in Yunnan first people's hospital, China, and it was used as host for phage isolation. The host strains were grown aerobically on LB plates or in LB broth (Difco, Detroit, MI, USA) that incubated at $37{ }^{\circ} \mathrm{C}$. Soft top agar containing LB broth was prepared with $0.5 \%$ agar $(\mathrm{M} / \mathrm{M})$ for phage plaque confirmation and $\mathrm{LB}$ agar plates were prepared with broth that supplemented with $1.8 \%$ agar (M/M). All strains of Salmonella stock cultures were stored at $-80{ }^{\circ} \mathrm{C}$ of LB broth (Difco, Detroit, MI, USA) which containing 20\% (V/V) glycerol.

\section{Phage isolation and purification}

Phages were isolated from residential sewage sump and pig slaughterhouse sump samples collected from Kunming city, China in September 2018. The method of isolate phages was according to the following methods with brief modified [45]. Briefly, $10 \mathrm{~g}$ of each sample was mixed with $20 \mathrm{~mL}$ sterile normal saline $(0.9 \% \mathrm{NaCl})$ buffered in $50 \mathrm{~mL}$ sterile centrifuge tube and then shake for $2 \mathrm{~h}$ using incubator with $200 \mathrm{rpm}$ at room temperature. Then, samples were centrifuged at $5000 \times \mathrm{g}$ for $15 \mathrm{~min}$ and filtered using $0.22 \mu \mathrm{m}$ filter membrane. $10 \mathrm{~mL}$ of each filtering medium was added to $30 \mathrm{~mL}$ of LB broth containing the $1 \%$ of overnight culture of the host strain and then incubated for $48 \mathrm{~h}$. After that, Cultures were centrifuged at $8000 \times \mathrm{g}$ for $15 \mathrm{~min}$ and the supernatant was filtered using $0.22 \mu \mathrm{m}$ filter membrane. 
The filtrate was diluted 10 times in series and mixing in $5 \mathrm{~mL}$ of molten $0.5 \%$ LB soft agar containing Salmonella $\left(2 \times 10^{8} \mathrm{cfu} / \mathrm{mL}\right)$, and immediately add to LB plate that containing 1.8 agar. Overnight culture and plaque formation was observed. Single phage plaque was selected for phage purification and repeat three times.

\section{The thermotolerance, optimum $\mathrm{pH}$, optimum MOI, growth curve and transmission electron microscopy (TEM) of isolated phages}

\section{Thermotolerance}

The phage stock was diluted to $1 \times 10^{8} \mathrm{pfu} / \mathrm{mL}$ with $\mathrm{LB}$ broth. Placed of $1 \mathrm{~mL}$ diluted phage in temperature controller of $4{ }^{\circ} \mathrm{C}, 25^{\circ} \mathrm{C}, 37^{\circ} \mathrm{C}, 42^{\circ} \mathrm{C}, 50^{\circ} \mathrm{C}, 60^{\circ} \mathrm{C}$ and $90^{\circ} \mathrm{C}$ for $1 \mathrm{~h}$, respectively. Following determination of phage titer at different temperature. The experiment was repeated three times.

\section{Optimum pH}

The phage stock was diluted to $1 \times 10^{8} \mathrm{pfu} / \mathrm{mL}$ with LB broth. Take $0.99 \mathrm{~mL}$ buffer liquid with $\mathrm{pH}$ of 3,4 , $5,6,7,8,9,10$ and 11 (Citrate buffer $50 \mathrm{mmol} / \mathrm{L}, \mathrm{pH} 3, \mathrm{pH}$ 4, pH 5; phosphate buffer $50 \mathrm{mmol} / \mathrm{L}, \mathrm{pH} 6, \mathrm{pH}$ 7, pH 8; Tris-HCl buffer $50 \mathrm{mmol} / \mathrm{L}, \mathrm{pH}$ 9; Sodium carbonate buffer $50 \mathrm{mmol} / \mathrm{L}, \mathrm{pH} 10, \mathrm{pH} 11)$ in $1.5 \mathrm{~mL}$ sterile centrifuge tube, added $0.01 \mathrm{~mL}$ diluted phage for titer of $1 \times 10^{8} \mathrm{pfu} / \mathrm{mL}$ to each tube. Place at room temperature for $1 \mathrm{~h}$ then determinationed titer of phage for different $\mathrm{pH}$ buffer. The experiment was repeated three times.

\section{Optimum MOI}

Multiplicity of infection (MOI) was the ratio of the number of phages added to the number of host bacteria at the time of initial infection. According to the MOI of $0.0001,0.001,0.01,0.11,10$ and 100 added phage stocks that diluted by LB broth into 10-fold series. Aliquots of each phage stocks were mixed with Salmonella paratyphi A NA3 cultures at $10^{8} \mathrm{cfu} / \mathrm{ml}$ to each ratio and were shocked culture at $37^{\circ} \mathrm{C}$ for $8 \mathrm{~h}$. The cultures were centrifuged at $10000 \times \mathrm{g}$ for $15 \mathrm{~min}$ at $4{ }^{\circ} \mathrm{C}$, then the supernatant was filtered by $0.22 \mu \mathrm{m}$ filter to obtain the phage increment solution, finally the titer of phage increment solution was determined through double plate method, the experiment was repeated three times.

\section{Adsorption rate and growth curve}

For adsorption rate measure, co-culture of phage KM16 $\left(1 \times 10^{8} \mathrm{pfu} / \mathrm{mL}\right)$ and logarithmic phase host bacterial suspension at the $\mathrm{MOI}$ of 0.1 , mixing uniformity and adsorbed at $15^{\circ} \mathrm{C}$, sampling $100 \mu \mathrm{L}$ at 0,2 , $4,6,8,10,15,20$ and $30 \mathrm{~min}$, respectively. The supernatant was taken after centrifugation of 12000 $\mathrm{g} / \mathrm{min}$ for $5 \mathrm{~min}$. The titer of phage was determined by double - plate method. For growth curve measure, added phage KM16 of $1 \times 10^{8} \mathrm{pfu} / \mathrm{mL}$ to LB culture containing $1 / 250$ seed fluid of host bacteria according the optimum $\mathrm{MOI}$ and shake culture at $37^{\circ} \mathrm{C}$, intermittent sampling was used to determine the titer of the phage. 


\section{Transmission electron microscopy}

The morphology of the phages particles was analyzed by transmission electron microscopy (TEM). Briefly, phage stock dilution (approximately $2 \times 10^{8}$ to $2 \times 10^{9} \mathrm{pfu} / \mathrm{mL}$ ) was deposited on copper grids with carbon-coated formvar films, stained with $2 \%$ uranyl-acetate $(\mathrm{pH} \mathrm{4.0)}$. Phage samples were imaged using a Philips EM 300 electron microscope, operated at $80 \mathrm{kV}$ at the Jiangnan university (Wuxi, China). Phages were classified and identified referring to the International Committee on Taxonomy of Viruses [46].

\section{Phage genomic DNA extraction, sequencing and bioinformatics analysis}

\section{Phage genomic extraction and restriction enzyme digestion}

Firstly, phage was purified from concentrated to a high titer stock using $10 \mathrm{kDa}$ filter (about $10^{9}$ to $10^{10}$ ). Purified phages were treated with RNase and DNase at $37^{\circ} \mathrm{C}$ for $1 \mathrm{~h}$. Then, Takara minibest viral RNA/DNA Extraction kit (Cat\#9766) was carried out to obtain purified phage genomic DNA. Restriction endonuclease Ecorl, Hind III, Not I and Xhol I were used for phage genome digestion, respectively.

\section{Sequencing and bioinformatics analysis}

Extracted phage genomic DNA was sequenced using a Illumina Hiseq (Sangon Biotech, China). The original sequencing data were evaluated by FastQC and assembled with SPAdes assembler software. The NCBI Blast compare with multiple databases of CDD, KOG, COG, NR, NT, PFAM, Swissprot and TrEMBL were used for function annotation information of gene protein sequence.

\section{Host-range determination and characteristic of host}

\section{Host-range determination}

The host range of the phage KM16 were determined by the spot test method [47]. The isolated strains were tested for susceptibility of phage KM16 (ten strains of Salmonella paratyphi A and two strains of Salmonella paratyphi B). Generally, each of $200 \mathrm{uL}$ reference strains $\left(10^{9} \mathrm{cfu} / \mathrm{mL}\right)$ was added to $5 \mathrm{~mL}$ of liquefied LB soft agar (LB broth with $0.5 \%$ agar), and poured over the LB $1.8 \%$ agar plate. Three minutes later, single drops of phage suspension were added and incubated at $37^{\circ} \mathrm{C}$ for $24 \mathrm{~h}$.

\section{Antimicrobial susceptibility testing}

\section{Antibiotic sensitivity testing}

Antibiotic sensitivity of the Salmonella paratyphi A and Salmonella paratyphi B were tested against seventeen antibiotics by minimal inhibitory concentration (MIC) method. The antimicrobials tested were: imipenem (IMI), cefoxitin (FOX), gentamicin (GM), amoxil (AMC), ertapenem (ETP), ceftriaxone (CTR), piperacillin (TZP), ampicillin (AMP), amikacin (AN), cefepime (FEP), tobramycin (TOB), aztreonam (AZM), selectrin (SXT), macrodantin (FTN), tigecycline (TGC), ciprofloxacin (CIP) and levofloxacin (LEV). 


\section{Phylogenetic and genetically specific analysis of host}

The genome of host Salmonella paratyphi were extracted by Takara minibest bacteria genomic DNA extraction kit. Then sequencing of $16 \mathrm{~S}$ gene was performed with $9 \mathrm{~F}$ upstream and 1512R downstream primers (F:GAGTTTGATCCTGGCTCAG; R:ACGGHTACCTTGTTACGACTT) in Sangon, China. Then biofilm and crisp-cas related gene sequencing was performed with primers in Sangon, China (Table 3). The phylogenetic analysis of $16 \mathrm{~S}$, biofilm and crisp-cas related gene of Salmonella paratyphi were performed using Molecular Evolutionary Genetics Analysis (MEGA7.0) software. The gene specificity of biofilm and crisp-cas related gene was studied using the software of Boiedit.

\section{Homology modelling of Salmonella fimA (pili) protein}

Homology modelling of Salmonella fimA (pili) protein tertiary structure was performed using SWISSMODEL online suit. The tertiary structure of Salmonella fimA among Salmonella paratyphi A-A, Salmonella paratyphi A-NA3 and Salmonella paratyphi B-H were predicted.

Table 3. Primers used for biofilm and crisp-cas related gene.

\begin{tabular}{lll}
\hline Primer name & Sequence 5'-3' $^{\prime}$ & Length \\
\hline $16 S-F$ & GAGTTTGATCCTGGCTCAG & 1504 \\
16S-R & ACGGHTACCTTGTTACGACTT & \\
Crisp 1-F & ATAATGCTGCCGTTGGTAA & 845 \\
Crisp 1-R & TTGATGAGTATGGTGGTTGTGGT & \\
SM-lsrK-F & GAABGTKCCGCCMAGMAC & 807 \\
SM-lsrK-R & ATGGCTCGACTCTKTACC & \\
SM-fimA-F & ATGACCTCTACTATTGCGAG & 525 \\
SM-fimA-R & TTATTCGTATTTCATGATAAAGG & \\
SM-invA-F & GTGAAATTATCGCCACGTTCGGGCAA & 261 \\
SM-invA-R & TCATCGCACCGTCAAAGGAACC & \\
SM-luxS-F & GCGACCACCTCAACGGTAA & 116 \\
SM-luxS-R & TTCAGCACATCCGCCATC & \\
\hline
\end{tabular}

\subsection{The different effects of phages and antibiotics on biofilms}

\section{Scanning electron microscopy}

Make first-phase preparations, A 48 - well cell slide was placed into a 24 - well plate. Seed solution was inoculated into $100 \mathrm{~mL} \mathrm{LB}$ culture solution at the rate of $1 / 250$. Inoculate $1 \mathrm{~mL}$ of bacterial solution into 24-well plate. One group, added phages, antibiotics, and mixtures of antibiotics and phages, respectively, nothing added as a control (The addition amount of phage was $\mathrm{MOI}=1$, The final concentration of kanamycin sulfate was $10 \mu \mathrm{g} / \mathrm{ml})$, Incubation $\left(37^{\circ} \mathrm{C}, 24 \mathrm{~h}\right)$. The other group, firstly culture for $12 \mathrm{~h}$, after that, added phages, antibiotics, and mixtures of antibiotics and phages, respectively, nothing added as a control (The addition amount of phage was $\mathrm{MOI}=1$, the final concentration of kanamycin sulfate was 10 $\mu \mathrm{g} / \mathrm{ml})$, Incubation $\left(37^{\circ} \mathrm{C}, 12 \mathrm{~h}\right.$ ). The cfu of each sample was measured by plate counting method. Following the recovered culture washed twice with PBS buffer; and fixed with $2.5 \%$ pre-cooling glutaraldehyde at room temperature for $3 \mathrm{~h}$ in dark place. Wash twice with PBS buffer, then dehydrated in an increasing ethanolic gradient $(15 \%, 30 \%, 50 \%, 70 \%, 100 \% \mathrm{v} / \mathrm{v})$, for $10 \mathrm{~min}$ at each step. Afterward, dry 
overnight and gilt, the results obtained through scanning electron microscope with an accelerating voltage $20 \mathrm{kV}$.

\section{Microplate reader detected the ability of biofilm formation}

Salmonella seed solution was inoculated in LB for the proportion 1/250 and overnight culture. Then 200 times dilution with LB and added to 96 -well plate (200 uL/hole), each sample has three multiple holes. One group, added phages, antibiotics, and mixtures of antibiotics and phages, respectively, nothing added as a control (The addition amount of phage was $\mathrm{MOI}=1$, the final concentration of kanamycin sulfate was $10 \mu \mathrm{g} / \mathrm{ml}$ ), incubation $\left(37^{\circ} \mathrm{C}, 24 \mathrm{~h}\right.$ ). The other group, firstly culture for $12 \mathrm{~h}$, after that, added phages, antibiotics, and mixtures of antibiotics and phages, respectively, nothing added as a control (The addition amount of phage was $\mathrm{MOI}=1$, the final concentration of kanamycin sulfate was $10 \mu \mathrm{g} / \mathrm{ml}$ ), incubation (37 ${ }^{\circ} \mathrm{C}, 12 \mathrm{~h}$ ). The bacterial population density $\left(\mathrm{OD}_{600} \mathrm{~nm}\right.$ ) was measured using a ELIASA (Thermo Scientific, EUA) and discarded bacteria solution. The wells washed twice with PBS to remove unattached cells, repeated three times, added $99 \%$ methanol and fix for 15 min, then discard methanol and dry at room temperature, following added $2 \%$ crystal violet and stain for $8 \mathrm{~min}$. Rinse the culture plate with running water until the water is colorless. After drying, measured the absorption light at $570 \mathrm{~nm}$ wavelength with a microplate reader. The experiment was repeated three times.

\section{Abbreviations}

$\mathrm{MOI}$, multiplicity of infection; MDR, multidrug-resistance; TEM, transmission electron microscopy; AR, antibiotic resistance.

\section{Declarations}

\section{Ethics approval and consent to participate}

Ethical approval was obtained from the Institutional Ethics Committee

(The First People's Hospital of Yunnan Province, Kunming, Yunnan, China ). The study protocol was in accordance with the Declaration of Helsinki for Human Research of 1974 (last modified in 2000). Written informed consent was received from each patient before sample collection.

\section{Consent for publication}

Not applicable.

\section{Availability of data and material}

All data generated or analyzed during this study are included in this published article and its supplementary information files.

\section{Competing interests}


The authors declare no conflict of interest.

\section{Funding}

This research was supported by the Foundation of the National Key Research and Development Program of China (2017YFC1601704), Projects 31522044, 31671909, and 31772034 of the National Natural Science Foundation of PR China and Program of Jiangsu Key Laboratory of Advanced Food Manufacturing Equipment \& Technology (FMZ201904), National First-class Discipline Program of Food Science and Technology (JUFSTR20180205). Sponsored by K.C.Wong Magna Fund in Ningbo University. Funding body had no role in design of the study, analysis, and interpretation of data.

\section{Authors' contributions}

L. J and R. Z Performed the experiments; Acquisition and analysis of data; Drafting of the manuscript; L. $J$ Technical or material support; R. Z Critical revision of the manuscript. All authors read and approved the final manuscript.

\section{Acknowledgments}

Not Applicable

\section{References}

[1] Hoffmann, S., Scallan, E. (2017). Chapter 2 - epidemiology, cost, and risk analysis of foodborne disease. In: Foodborne Diseases, Third edition. Academic Press, 31-63.

[2] Jones, F. T. A review of practical Salmonella control measures in animal feed. (2011). Journal of Applied Poultry Research, 20(1), 102-113.

[3] Deng, X., Ran, L., Wu, S. (2012). Laboratory-based surveillance of non-typhoidal Salmonella infections in Guangdong Province, China. Foodborne Pathogens \& Disease. 9, 305-312. https://doi:

10.1089/fpd.2011.1008.

[4] Majowicz, S. E., Musto, J., Scallan, E. (2010). The global burden of nontyphoidal Salmonella gastroenteritis. Clinical Infectious Diseases. 50(6), 882-889. https://doi: 10.1086/650733.

[5] Branda, S. S., Vik, A., Friedman, L., Kolter, R. (2005). Biofilms: The matrix revisited.Trends in Microbiology. 13, 20-26. https://DOI: 10.1016/j.tim.2004.11.006.

[6] Flemming, H. C., Wingender, J. (2010). The biofilm matrix. Nat Rev Microbiol. 8, 623-33. https://doi: $10.1038 /$ nrmicro2415.

[7] Hall-Stoodley, L., Costerton, J. W., Stoodley, P. (2004). Bacterial biofilms: From the natural environment to infectious diseases. Nature Reviews Microbiology, 2(2). 
[8] Donlan, R. M., Costerton, J. W. (2002). Biofilms: Survival mechanisms of clinically relevant microorganisms. Clinical Microbiology Reviews. 15, 67.

[9] Marchand, S., De Block, J., De Jonghe ,V., Coorevits, A., Heyndrickx, M., Herman, L. (2012). Biofilm formation in milk production and processing environments; influence on milk quality and safety. Comprehensive Reviews in Food Science and Food Safety. 11(2), 133-147.

[10] Davies, D. (2003). Understanding biofilm resistance to antibacterial agents. Nature Reviews Drug Discovery, 2, 114-122. https://DOI:10.1038/nrd1008

[11] Luppens, S. B., Reij, M. W., van der Heijden, R. W., Rombouts, F. M., Abee, T. (2002). Development of a standard test to assess the resistance of Staphylococcus aureus biofilm cells to disinfectants. Applied and Environmental Microbiology. 68(9), 4194-4200. https://DOI:10.1128/aem.68.9.4194-4200.2002

[12] Penesyan, A., Gillings, M., Paulsen, I. T. (2015). Antibiotic discovery: Combatting bacterial resistance in cells and in biofilm communities. Molecules. 20(4), 5286-5298.

[13] Kumari, S., Sarkar, P. K. (2016). Bacillus cereus hazard and control in industrial dairy processing environment. Food Control 69,20-29.

[14] Jay, J. M. (2000). Modern food microbiology. 6th ed. Gaithersburg, MD: Aspen Publishers Inc. P, 679. [15] Endersen, L., O'Mahony, J., Hil,I C. (2014). Phage therapy in the food industry. Annu Rev Food Sci Techno. 5, 327-349

[16] Chang, Y., Shin, H., Lee, J. H., Park, C. J., Paik, S. Y., Ryu, S. (2015). Isolation and genome characterization of the virulent Staphylococcus aureus bacteriophage SA97. Viruses. 7, 5225-5242. https://doi: 10.3390/v7102870.

[17] Kutter, E., Sulakvelidze, A. (2005). Bacteriophages: Biology and Applications. CRC Press, Boca Raton, FL.

[18] Gutierrez, D., Rodrguez-Rubio, L., Martnez, B., Rodrguez, A., Garca, P. (2016). Bacteriophages as weapons against bacterial biofilms in the food industry. Front Microbiol. 7, 825. https://doi: $10.3389 /$ fmicb.2016.00825.

[19] McCallin, S., Alam Sarker, S., Barretto, C., Sultana, S., Berger, B., Huq, S., Krause, L., Bibiloni, R., Schmitt, B., Reuteler, G., Brussow, H. (2013). Safety analysis of a Russian phage cocktail: from metagenomic analysis to oral application in healthy human subjects. Virology. 443, 187-196. https://doi: 10.1016/j.virol.2013.05.022.

[20] Ahn, J., Kim, S., Jung, L. S., Biswas, D. (2013). In vitro assessment of the susceptibility of planktonic and attached cells of foodborne pathogens to bacteriophage P22-mediated Salmonella lysates. J Food Prot. 76, 2057-2062. https://doi: 10.4315/0362-028X.JFP-13-183. 
[21] Chandra, M., Thakur, S., Chougule, S .S., Narang, D., Kaur, G., Sharma, N. S. (2015). Combined effect of disinfectant and phage on the survivality of Salmonella Typhimurium and its biofilm phenotype. Int $J$ Food Safety. 1725-1731.

[22] Garcia, K. C. O. D., Corrêa, I. M. O., Pereira, L. Q., Silva, T. M., Mioni, M. S. R., Izidoro, A. C. M., Bastos, I. H. V., Goncalves, G. A. M., Okamoto, A. S., Andreatti Filho, R. L. (2017). Bacteriophage use to control Salmonella biofilm on surfaces present in chicken slaughterhouses. Poult Sci. 96, 3392-3398. https://doi: 10.3382/ps/pex124.

[23] Gong, C, Jiang, X. (2017). Application of bacteriophages to reduce Salmonella attachment and biofilms on hard surfaces. Poult Sci. 96, 1838-1848. https://doi:10.3382/ps/pew463.

[24] Knezevic, P., Petrovic, O. (2008). A colorimetric microtiter plate method for assessment of phage effect on Pseudomonas aeruginosa biofilm. J Microbiol Methods. 74, 114-118. https://doi:10.1016/j.mimet.2008.03.005.

[25] Abubakar, S., Suleiman, B. H., Abbagana, B. A., Mustafa, I. A., and Musa, I. A. (2016). Novel uses of bacteriophages in the treatment of human infections and antibiotic resistance. Am. J. Biosci. 4, 34-40. doi: 10.11648/j.ajbio.20160403.13

[26] Merabishvili, M., Pirnay, J.-P., Verbeken, G., Chanishvili, N., Tediashvili, M., Lashkhi, N., et al. (2009). Quality-controlled small-scale production of a well defined bacteriophage cocktail for use in human clinical trials. PLoS ONE 4:e4944. doi: 10.1371/journal.pone.0004944

[27] Mead, P. S., Slutsker, L., Dietz, V., McCaig, L. F, Bresee, J. S, Shapiro, C., Grifn, P. M., Tauxe, R. V. (1999). Food-related illness and death in the United States. Emerg Infect Dis. 5, 607. https://DOI: 10.3201/eid0505.990502.

[28] Centers for Disease Control and Prevention (CDC). (2018). Salmonella - information for healthcare professionals and laboratories. [accessed: $2018 \mathrm{Mar}$ 9] http://www.cdc.gov/Salmonella/general/technical.html.

[29] Laghari, G. S., Hussain, Z., Hussain, S. Z. M. (2019). Antimicrobial Susceptibility Patterns of Salmonella Species in Southern Pakistan. Cureus. 3, 11(4):e4379. http://doi: 10.7759/cureus.4379.

[30] Lu, Y., Wen, Y., Hu, G. (2019). Genomic Sequence Analysis of the Multidrug-Resistance Region of Avian Salmonella enterica serovar Indiana Strain MHYL. Microorganisms. 9, 7(8). pii: E248. http://doi: 10.3390/microorganisms7080248.

[31] Sritha, K. S., Bhat, S. G. (2018). Genomics of Salmonella phage $\Phi$ Stp1: candidate bacteriophage for biocontrol. Virus Genes. 54(2), 311-318. http://doi: 10.1007/s11262-018-1538-3. Epub 2018 Feb 24.

[32] Thanki A. M., Brown, N., Millard, A. D. (2019). Genomic Characterization of Jumbo Salmonella Phages That Effectively Target United Kingdom Pig-Associated Salmonella Serotypes. 
Front Microbiol. 10, 1491. http://doi: 10.3389/fmicb.2019.01491. eCollection 2019.

[33] Dunne, M., Denyes, J. M., Arndt, H. (2018). Salmonella Phage S16 Tail Fiber Adhesin Features a Rare Polyglycine Rich Domain for Host Recognition. Structure. 26, 1573-1582.e4. http://doi:

10.1016/j.str.2018.07.017. Epub 2018 Sep 20.

[34] Pham-Khanh, N. H., Sunahara, H., Yamadeya, H. (2019). Isolation, Characterisation and Complete Genome Sequence of a Tequatrovirus Phage, Escherichia phage KIT03, Which Simultaneously Infects Escherichia coli 0157:H7 and Salmonellaenterica. Curr Microbiol. 76(10), 1130-1137. http://doi: 10.1007/s00284-019-01738-0. Epub 2019 Jul 24.

[35] Al-Shabib, N. A., Husain, F. M., Ahmad, I., Khan, M. S., Khan, R. A., \& Khan, J. M. (2017). Rutin inhibits mono and multi-species biofilm formation by foodborne drug resistant Escherichia coli and Staphylococcus aureus. Food Control. 79, 325-332.

[36] Grant, A., Hashem, F., Parveen, S. (2016). Salmonella and Campylobacter. antimicrobial resistance and bacteriophage control in poultry. Food Microbiol. http://53:104-109. doi: 10.1016/j.fm.2015.09.008.

[37] Shi, X., Zhu, X. (2009). Biofilm formation and food safety in food industries. Trends Food Sci Technol. 20, 407-413. http://doi: 10.1016/j.tifs.2009.01.054.

[38] Cappitelli, F., Polo, A.,Villa, F. (2014). Biofilm formation in food processing environments is still poorly understood and controlled. Food Engineering Reviews. 6, 29-42.

[39] Simoes, M., Simoes, L. C., Vieira, M. J. (2010). A review of current and emergent biofilm control strategies. Lwt-Food Science and Technology. 43(4), 573-583.

[40] Wu, M., Hu, K., Xie, Y., Liu, Y., Mu, D., Guo, H., et al. (2019). A Novel Phage PD-6A3, and Its Endolysin Ply6A3, With Extended Lytic Activity Against Acinetobacter baumannii. Front. Microbiol. 9:3302. doi: 10.3389/fmicb.2018.03302.

[41] Sergueev, K. V., Filippov, A. A., Farlow, J., Su, W., Kvachadze, L., Balarjishvili, N., et al. (2019). Correlation of host range expansion of therapeutic bacteriophage Sb-1 with allele state at a hypervariable repeat locus. Appl Environ Microbiol. 85, e01209-19. https:// doi.org/10.1128/AEM.01209-19.

[42] Tomasz, O., Katarzyna, D. W., Michal, A., Grzegorz, G., Barbara, M., Slawomir, W., et al. (2019). Pseudomonas aeruginosa PA5oct Jumbo Phage Impacts Planktonic and Biofilm Population and Reduces Its Host Virulence. Viruses. 11, 1089; doi:10.3390/v11121089.

[43] Benešík, M., Nováček, J., Janda, L., Dopitová, R., Pernisová, M., Melková, K., et al. (2018). Role of $\mathrm{SH} 3 \mathrm{~b}$ binding domain in a natural deletion mutant of Kayvirus endolysin LysF1 with a broad range of lytic activity. Virus Genes. 4, 130-139. doi: 10.1007/s11262-017-1507-2. 
[44] Hoai, T. D., Nishiki, I., Yoshida, T., Nakai, T. (2018). Host range and influence of a cell capsule on the phage efficacy of three Lactococcus garvieae lytic phages. Dis Aquat Organ. 22, 81-86. doi: 10.3354/dao03212.

[45] Park, M., Lee, J. H., Shin, H., Kim., Choi, J., Kan, D. H., Heu, S., Ryu, S. (2012). Characterization and comparative genomic analysis of a novel bacteriophage, SFP10, simultaneously inhibiting both Salmonella enterica and Escherichia coli 0157:H7. Appl Environ Microbiol. 78, 58-69. http://doi: 10.1128/AEM.06231-11. Epub 2011 Oct 21.

[46] Rodhain, F. (1995). Classification and nomenclature of Viruses. In: Francki RIB, Fauquet, CM, Knudson DL, Brown, F. (Eds.) 5th Report of the Internationalcommittee-for-virus-taxonomy - French. vol. 2 Parasite, 95-95.

[47] Chopin, M. C., Chopin, A., Roux, C. (1976). Definition of bacteriophage groups according to their lytic action on mesophilic lactic streptococci. Applied and Environmental Microbiology. 32, 741-746.

\section{Supplemental Legends}

Table S1. Identified protein-coding genes (open reading frames (ORFs) of phage KM16 complete genome.

\section{Figures}
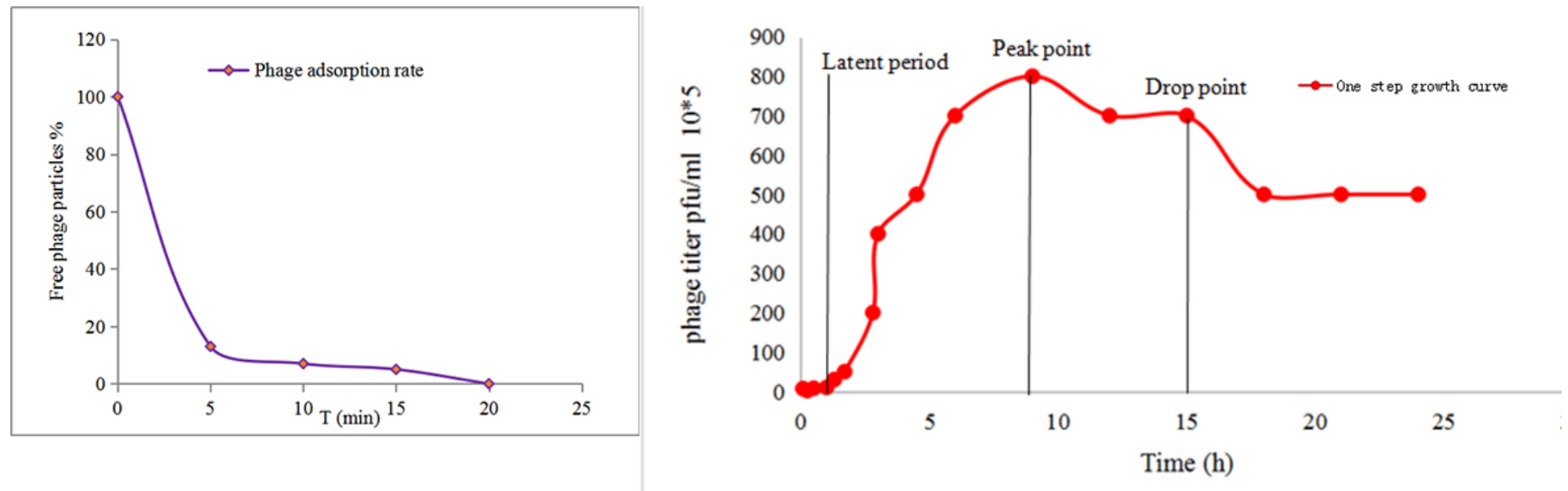

\section{Figure 1}

Adsorption rate and population dynamics of phage KM16 inoculate in Salmonella paratyphi A NA3. 


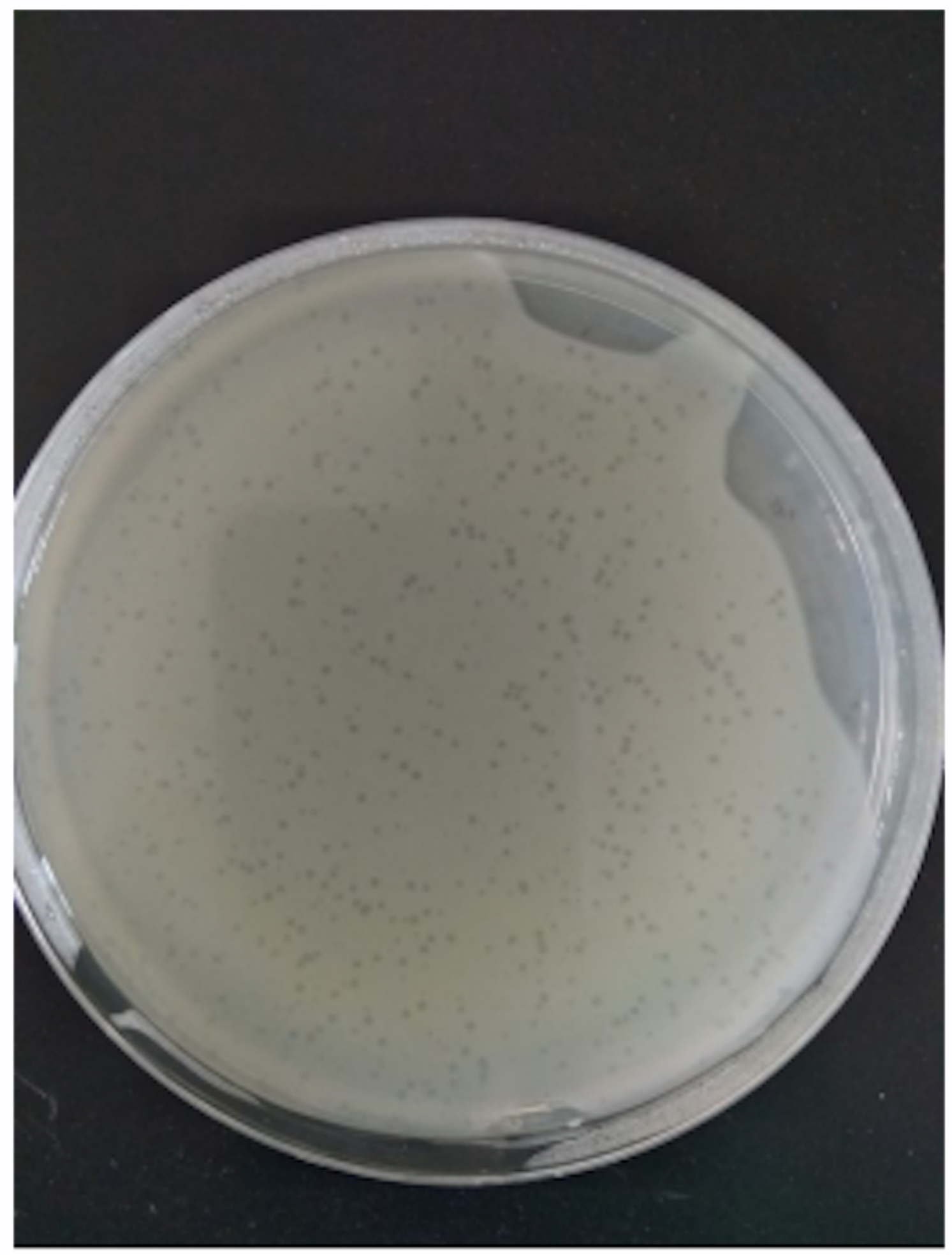

Figure 2

Plaques formed by phage KM16, the host strains of Salmonella paratyphi A NA3 after an overnight incubation at $37^{\circ} \mathrm{C}$. 


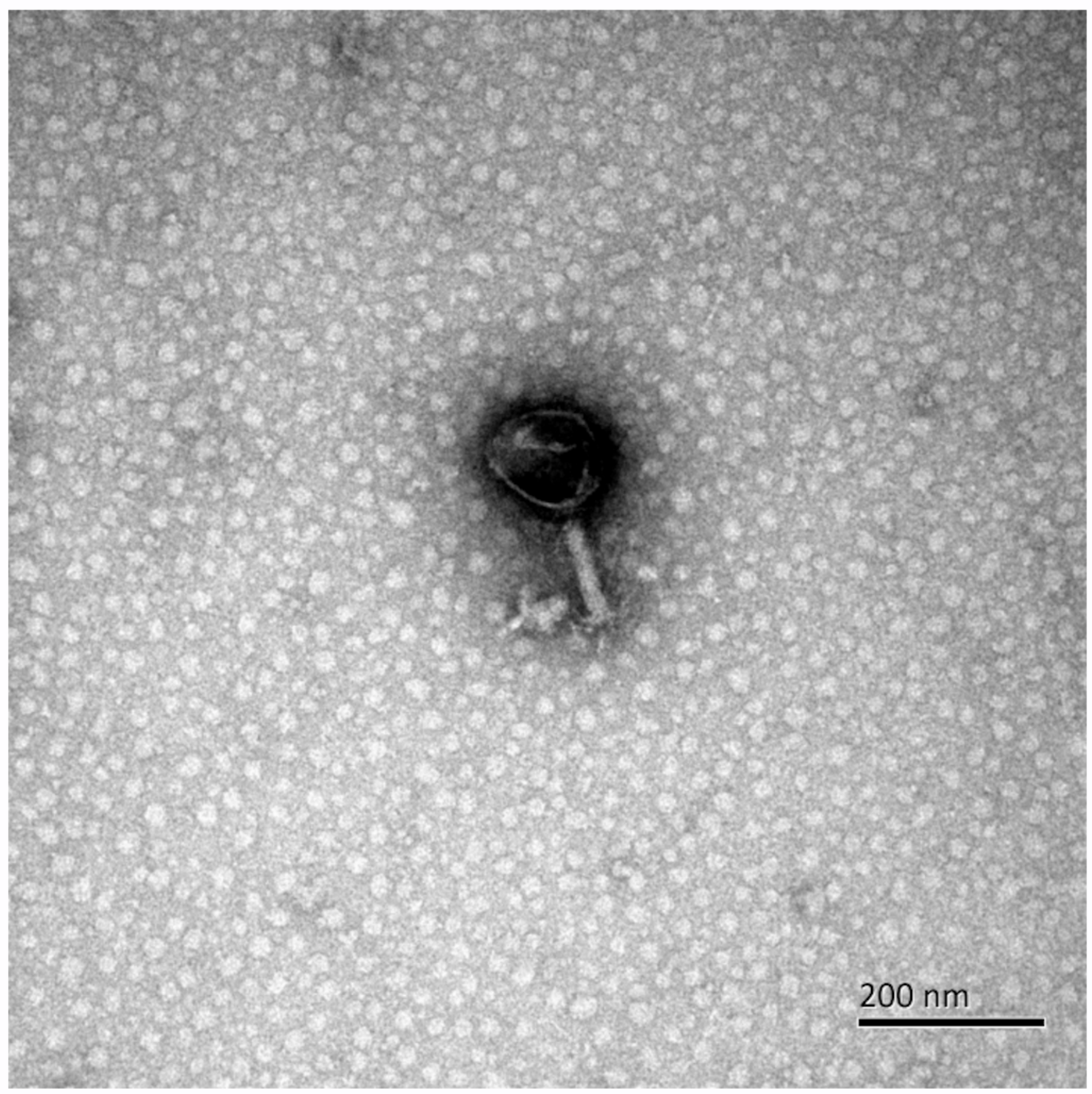

\section{Figure 3}

Morphological features of phage KM16 with host of Salmonella paratyphi A NA3 by transmission electron microscopy (TEM). 


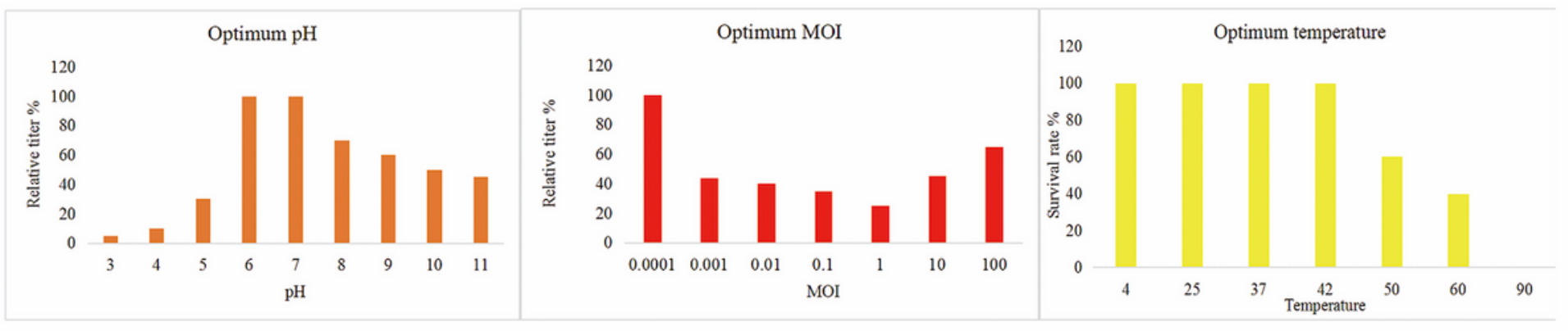

Figure 4

Optimum temperature, $\mathrm{pH}$ and $\mathrm{MOI}$ of isolated phage $\mathrm{KM} 16$.

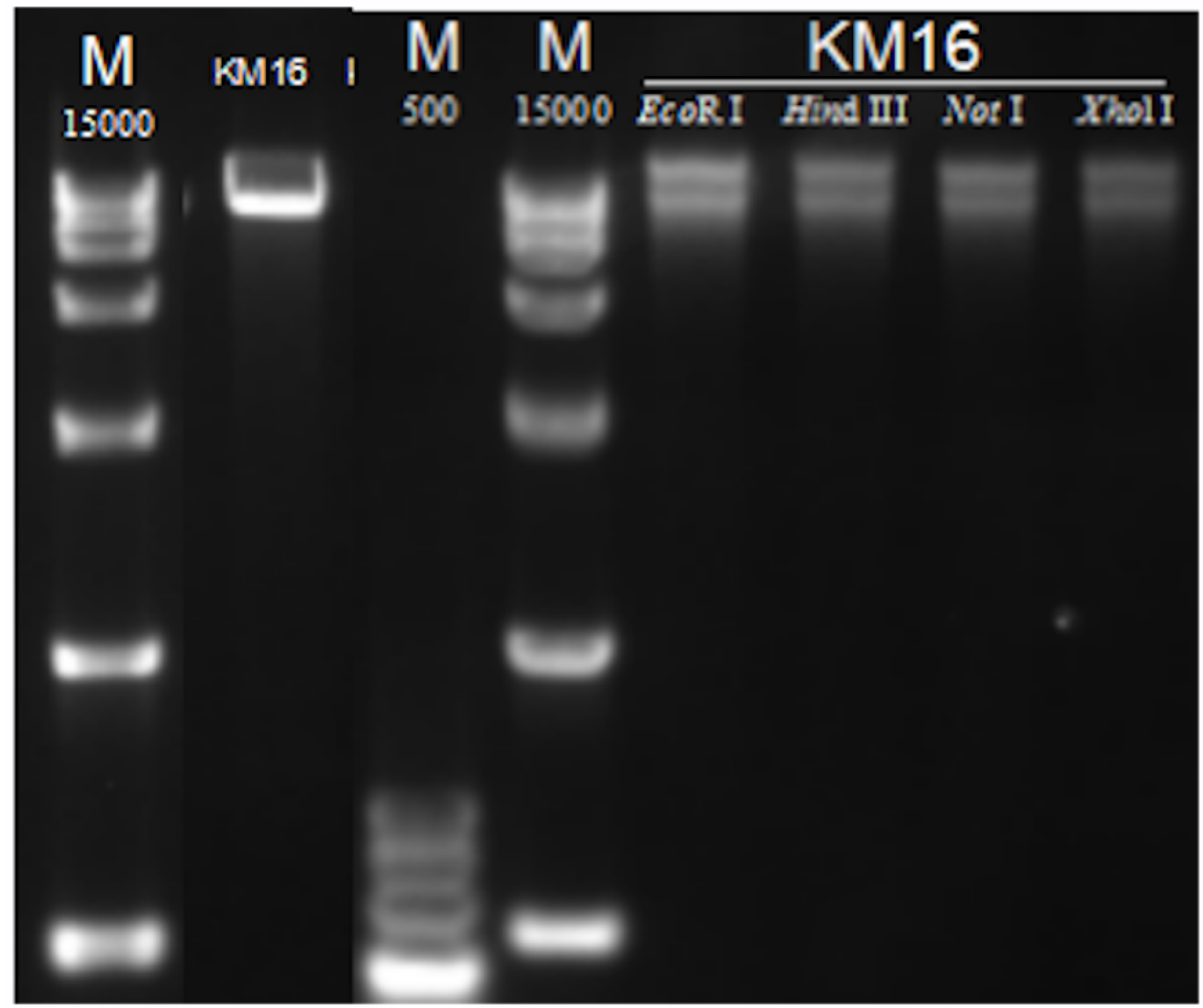

Figure 5 

Xhol I.

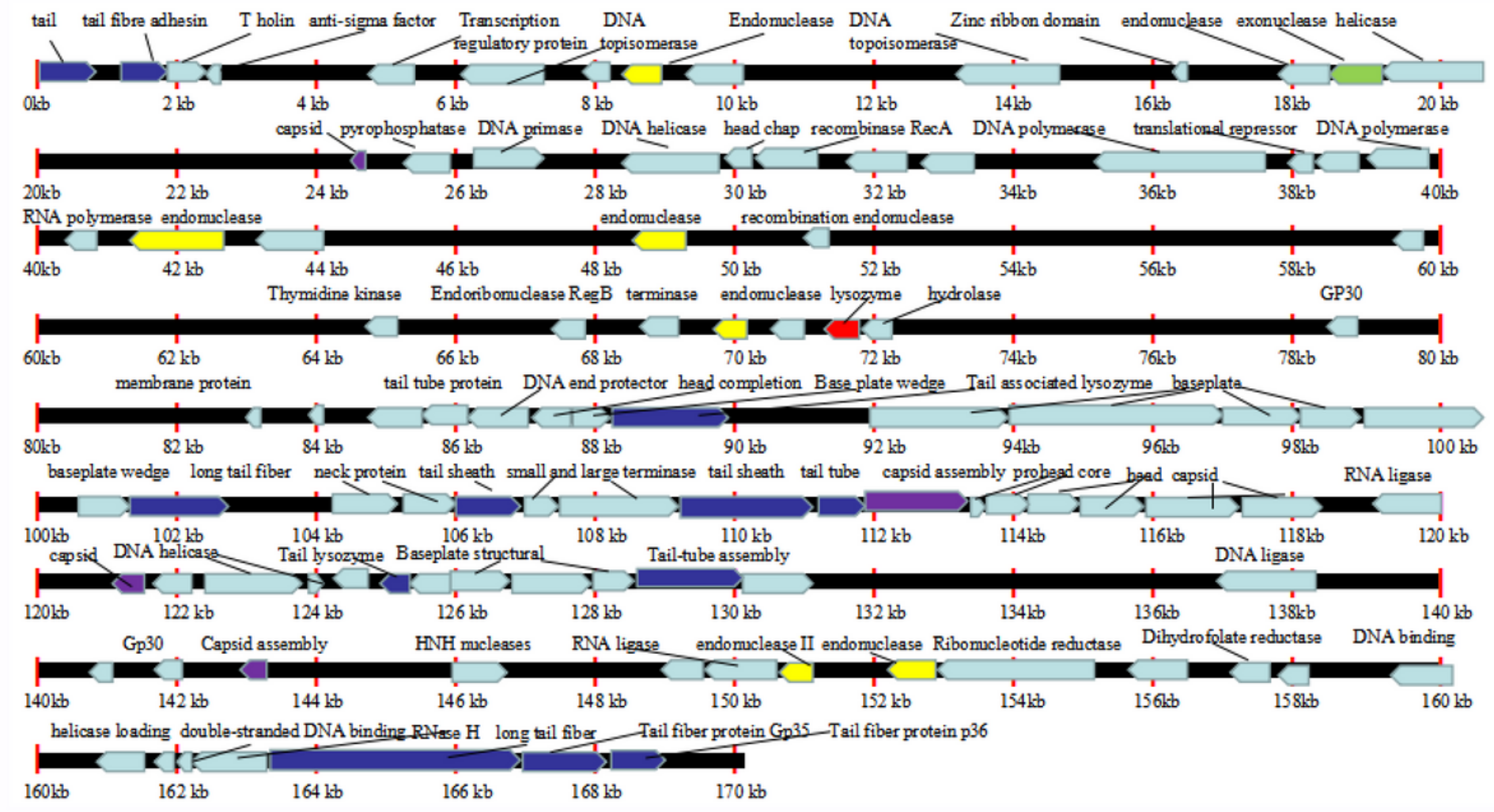

\section{Figure 6}

Line map of the phage KM16 genome. In the KM16 track, genes colored red instructions for lysozyme and genes colored yellow instructions for endonuclease.The arrows represent the ORFs and point the direction of transcription. 

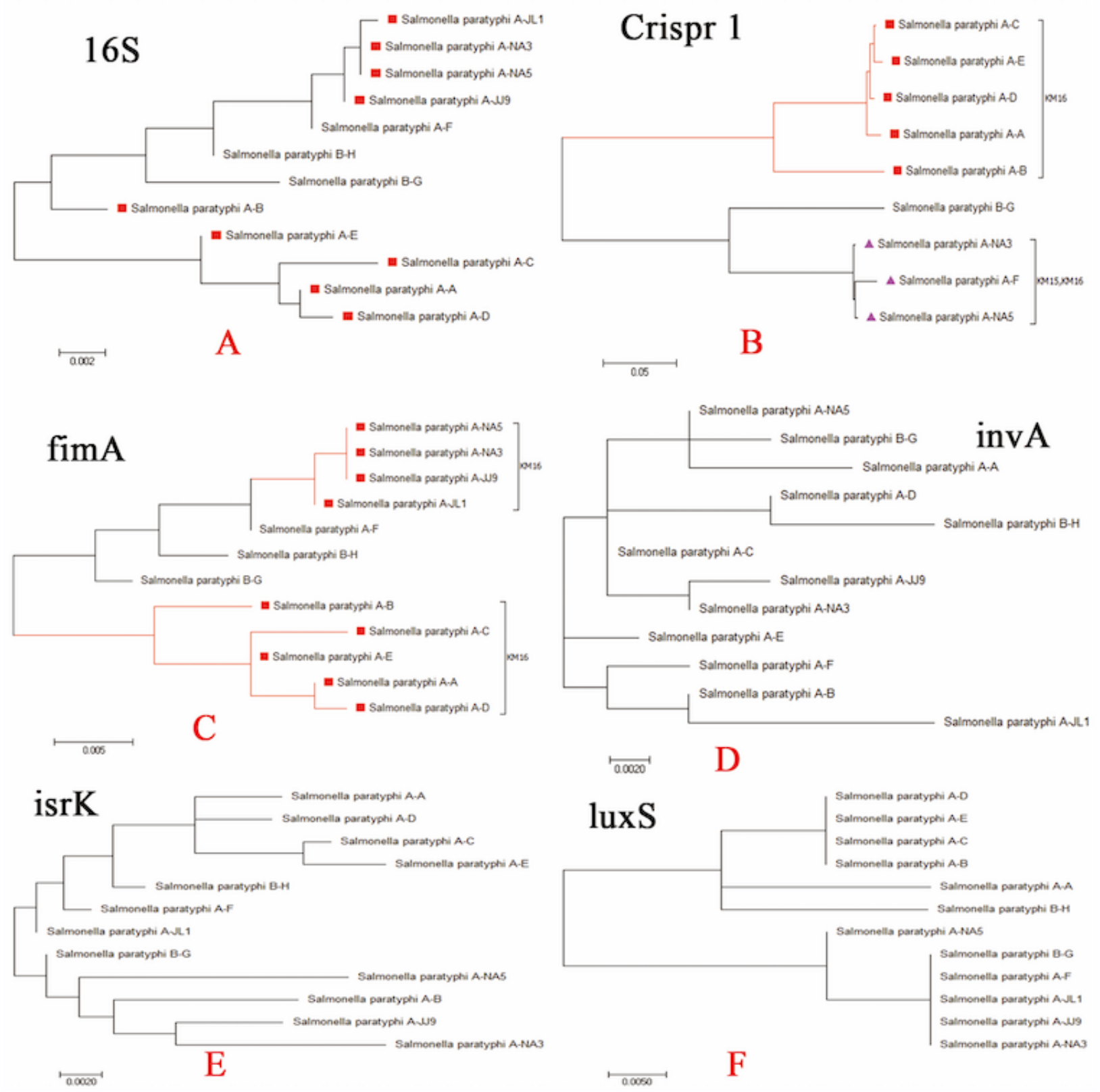

\section{Figure 7}

Phylogenetic tree of Salmonella paratyphi genes of $16 \mathrm{~S}$, crispr 1, fimA, invA, isrK and luxS. The phylogenetic tree were constructed using the Maximum Likelyhood phylogeny test and bootstrap values were set for 1000 repetitions. The phylogenetic tree of $16 \mathrm{~S}$ gene indicated that Salmonella paratyphi which can be lysed are more closely related. The results showed that lytic spectrum consistent with the gene of crispr 1 and fimA, but not correlated with the gene of invA, isrK and luxS. (Red square denotes the Salmonella strains lysed by KM16). 


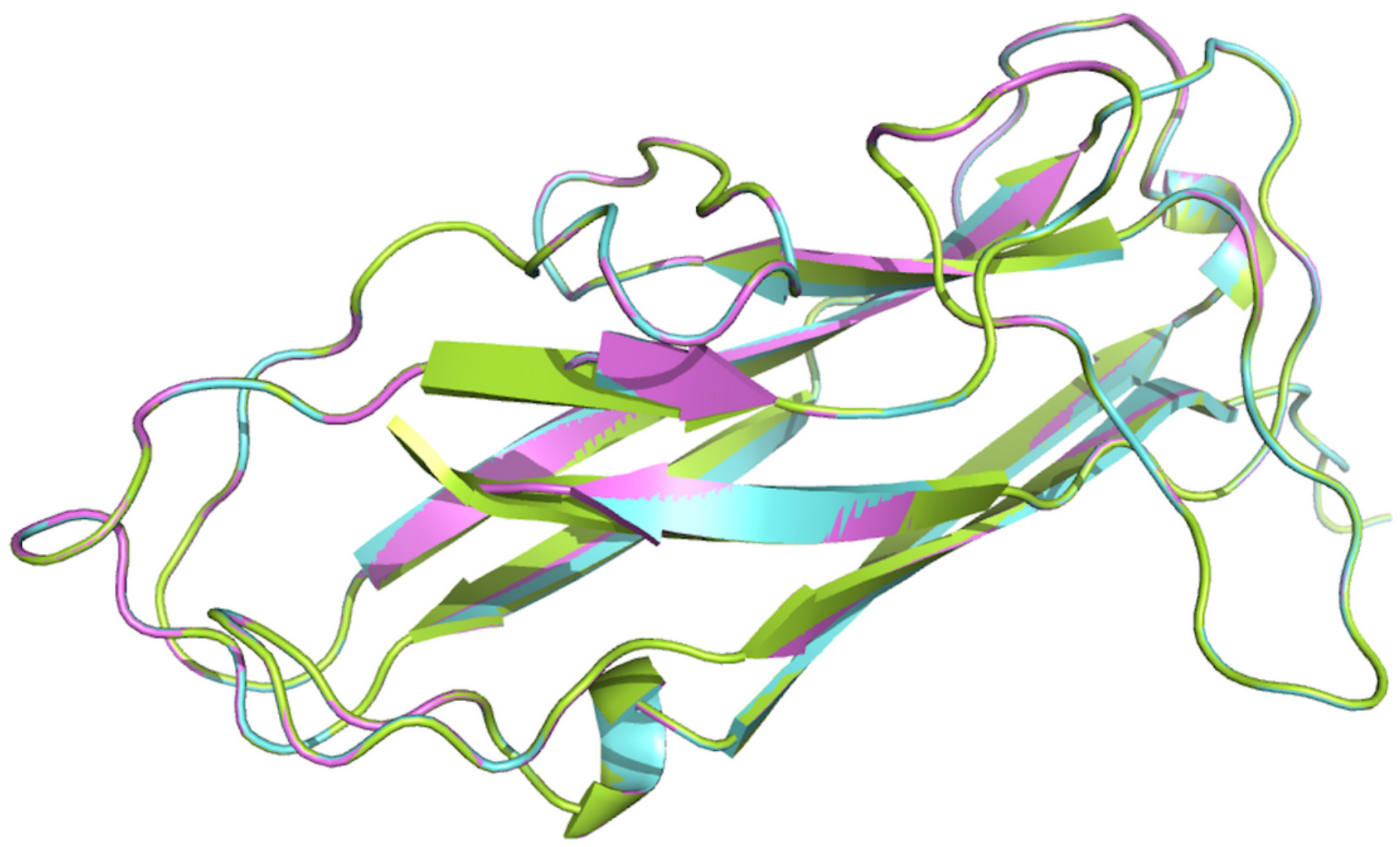

Figure 8

Predicted tertiary structure of Salmonella fimA protein. Superposition of Salmonella paratyphi A-A (blue), Salmonella paratyphi A-NA3 (purple) and Salmonella paratyphi B-H (green) (https://www.rcsb.org/structure/6erj). 


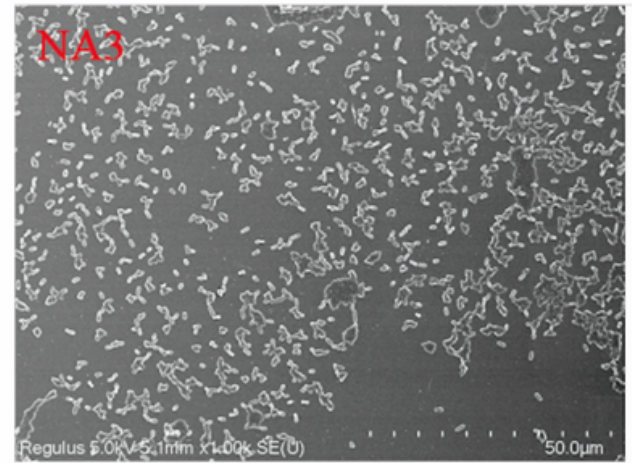

A

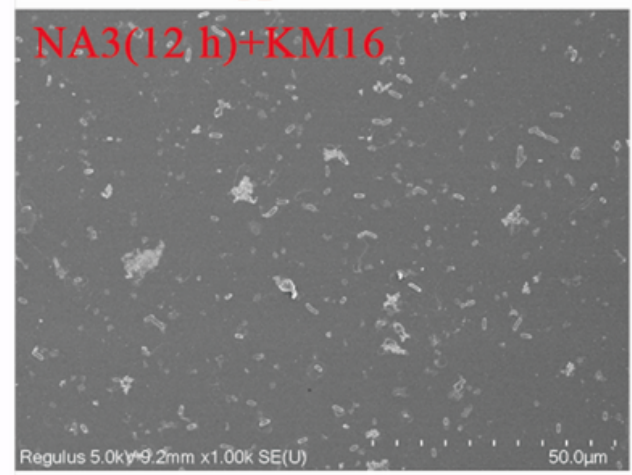

$\mathrm{D}$

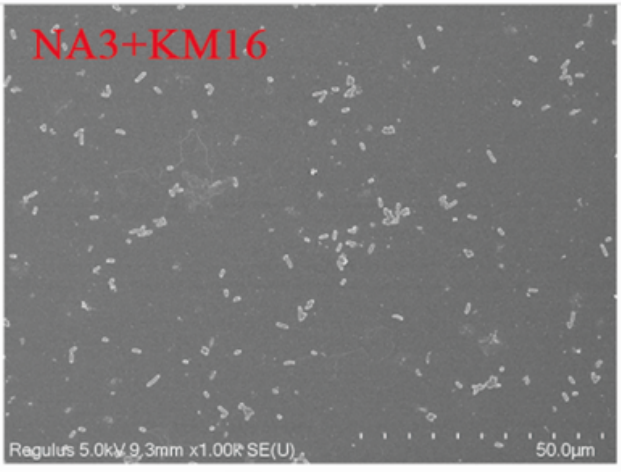

B

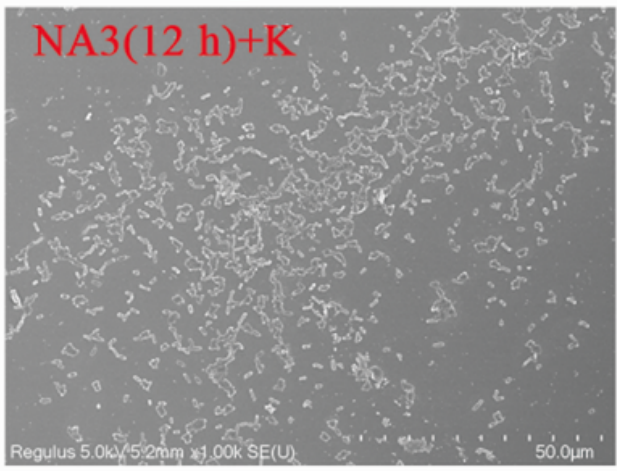

$\mathrm{E}$

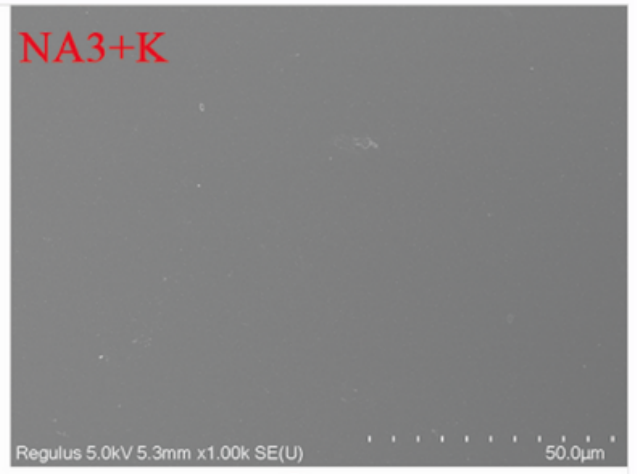

$\mathrm{C}$

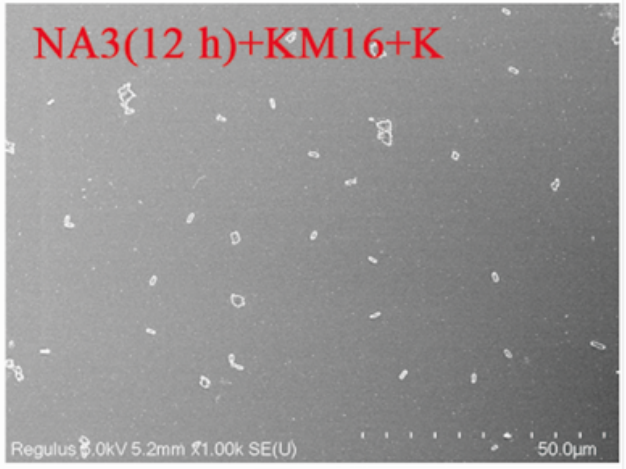

$\mathrm{F}$

\section{Figure 9}

Scanning electron micrograph (SEM) of Salmonella paratyphi A NA3 colonization before and after phage KM16 (MOI=0.1) and kanamycin sulfate $(10 \mu \mathrm{g} / \mathrm{mL})$ application to biofilms formed on round coverslip. (A) Salmonella paratyphi A NA3 seed solution inoculation at a rate of 1/250 and culture for $24 \mathrm{~h}$, (B) A added phage KM16 (MOI=0.1), (C) A added kanamycin sulfate $(10 \mu \mathrm{g} / \mathrm{mL})$. (D) Salmonella paratyphi A NA3 seed solution inoculation at a rate of $1 / 250$ and culture for $12 \mathrm{~h}$, then phage KM16 (MOI=0.1) was added and cultured for $12 \mathrm{~h}$, (E) Salmonella paratyphi A NA3 seed solution inoculation at a rate of 1/250 and culture for $12 \mathrm{~h}$, then kanamycin sulfate $(10 \mu \mathrm{g} / \mathrm{mL})$ was added and cultured for $12 \mathrm{~h}$, (F) Salmonella paratyphi A NA3 seed solution inoculation at a rate of $1 / 250$ and culture for $12 \mathrm{~h}$, then phage KM16 (MOI=0.1) and kanamycin sulfate $(10 \mu \mathrm{g} / \mathrm{mL})$ were added and cultured for $12 \mathrm{~h}$. (1, 000× magnification) 

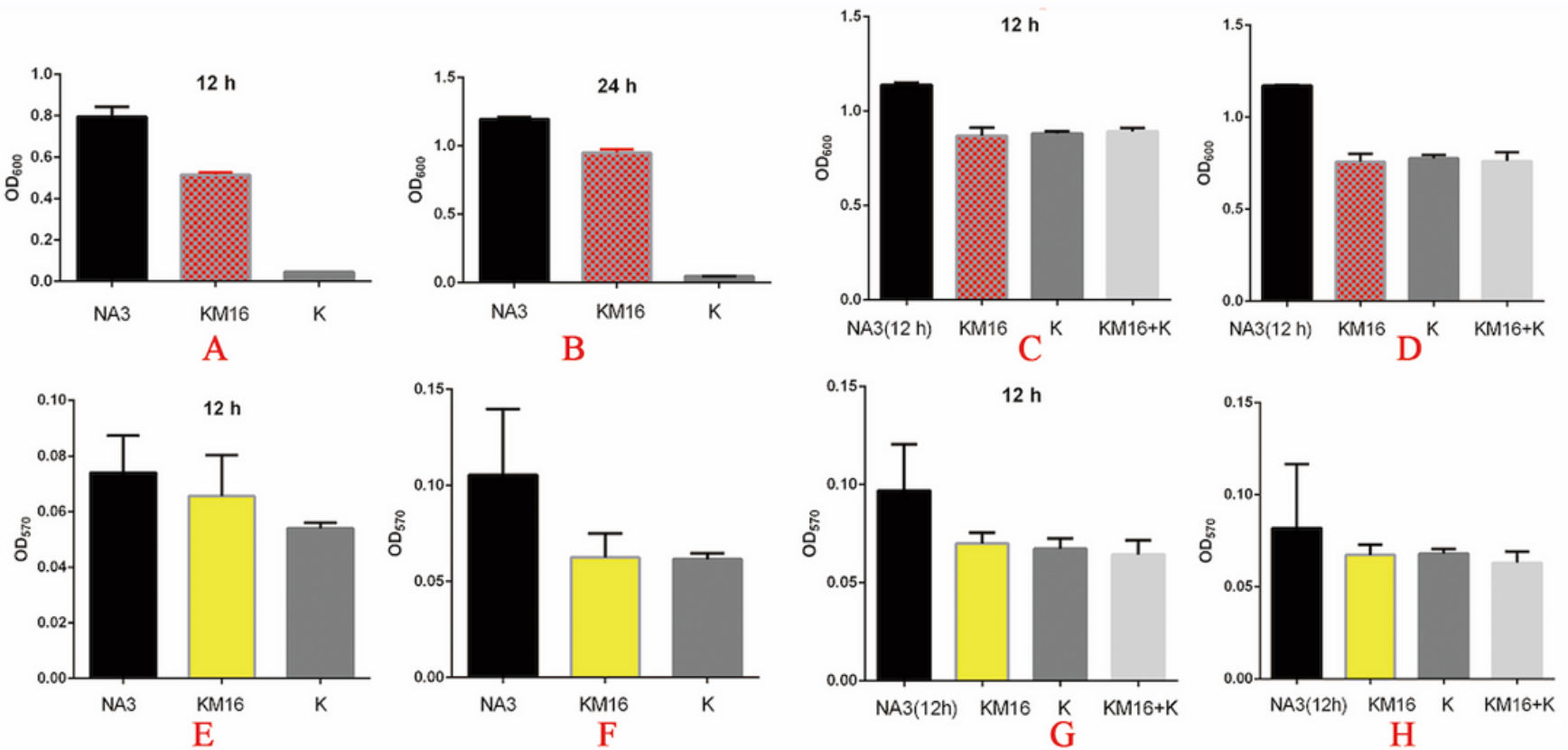

Figure 10

Effects of phages and kanamycin sulfate $(10 \mu \mathrm{g} / \mathrm{mL})$ on biofilms. $(A, B)$ Effects of phage KM16 and kanamycin sulfate $(10 \mu \mathrm{g} / \mathrm{mL})$ on Salmonella paratyphi A NA3 seed solution (inoculation at a rate of 1/250) growth that culture for $12 \mathrm{~h}$ and $24 \mathrm{~h}$ (OD600). (E, F) Effects of phage KM16 and kanamycin sulfate $(10 \mu \mathrm{g} / \mathrm{mL}$ ) on Salmonella paratyphi A NA3 seed solution (inoculation at a rate of $1 / 250$ ) biofilm that culture for $12 \mathrm{~h}$ and $24 \mathrm{~h}$ (OD570). (C, D) Effects of phage KM16 and kanamycin sulfate $(10 \mu \mathrm{g} / \mathrm{mL})$ on Salmonella paratyphi A NA3 seed solution (inoculation at a rate of $1 / 250$ ) growth, first culture for $12 \mathrm{~h}$, then phage KM16 and kanamycin sulfate $(10 \mu \mathrm{g} / \mathrm{mL})$ were added and cultured for $12 \mathrm{~h}$ and $24 \mathrm{~h}$ (OD600). (G,H) Effects of phage KM16 and kanamycin sulfate $(10 \mu \mathrm{g} / \mathrm{mL})$ on Salmonella paratyphi A NA3 seed solution (inoculation at a rate of 1/250) biofilm, first culture for $12 \mathrm{~h}$, then phage KM16 and kanamycin sulfate $(10 \mu \mathrm{g} / \mathrm{mL})$ were added and cultured for $12 \mathrm{~h}$ and $24 \mathrm{~h}$ (OD570,). 

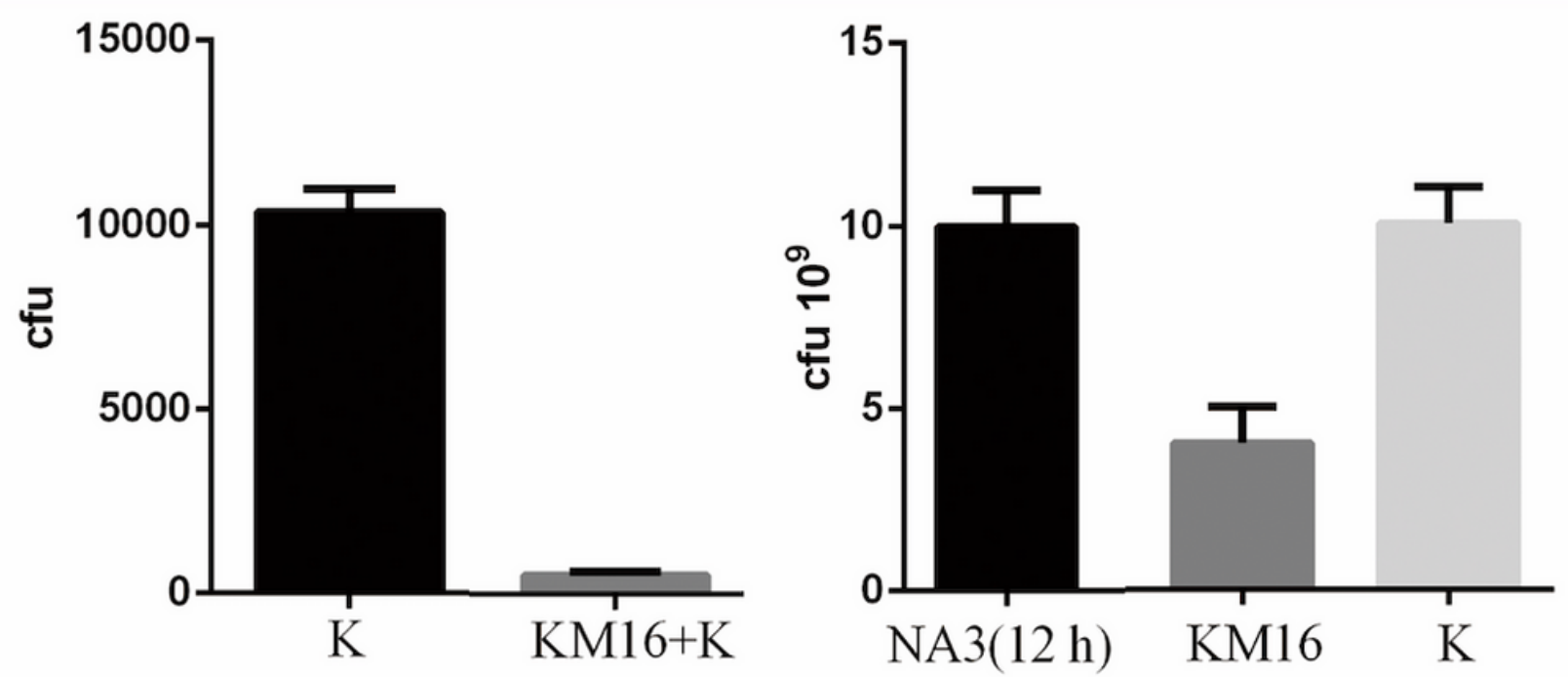

Figure 11

Effects of phages and kanamycin sulfate $(10 \mu \mathrm{g} / \mathrm{mL})$ on colony-forming unit of Salmonella paratyphi A NA3. (A) Effects of phage KM16 and kanamycin sulfate $(10 \mu \mathrm{g} / \mathrm{mL})$ on Salmonella paratyphi A NA3 seed solution (inoculation at a rate of 1/250) that culture for $24 \mathrm{~h}$. (B) Effects of phage KM16 and kanamycin sulfate $(10 \mu \mathrm{g} / \mathrm{mL}$ ) on Salmonella paratyphi A NA3 seed solution (inoculation at a rate of $1 / 250$ ), first culture for $12 \mathrm{~h}$, then phage KM16 and kanamycin sulfate $(10 \mu \mathrm{g} / \mathrm{mL})$ were added and cultured for $12 \mathrm{~h}$.

\section{Supplementary Files}

This is a list of supplementary files associated with this preprint. Click to download.

- Supplementarylnformationfile.doc

- Tables1.xls 